\title{
Intraoperative findings in primary caesarean section for non-reassuring fetal status and its correlation with cardiotocography
}

\author{
Nisha Bhatia*, Krishna Kumari M.
}

Department of Obstetrics and Gynecology, Apollo Institute of Medical Sciences and Research, Hyderabad, Telangana, India

Received: 31 March 2018

Accepted: 30 April 2018

*Correspondence:

Dr. Nisha Bhatia,

E-mail: nish_178@yahoo.co.in

Copyright: (C) the author(s), publisher and licensee Medip Academy. This is an open-access article distributed under the terms of the Creative Commons Attribution Non-Commercial License, which permits unrestricted non-commercial use, distribution, and reproduction in any medium, provided the original work is properly cited.

\begin{abstract}
Background: Cardiotocography plays an important role in diagnosing nonreassuring fetal status during labour, which is a leading cause for caesarean section among primigravida. These abnormal cardiotocographic traces may or may not translate into intraoperative findings of meconium stained liquor or low APGAR at birth. Hence a study is warranted to understand their correlation, thereby demonstrating the utility of cardiotocography in diagnosing nonreassuring fetal status. The objective of the study was to assess the correlation of intraoperative findings and neonatal outcome in primigravida undergoing emergency caesarean section for nonreassuring fetal status with cardiotocography.

Methods: A retrospective analysis of 104 case records of primigravida undergoing emergency caesarean section for fetal distress at Department of Obstetrics and Gynecology, Apollo Institute of Medical Sciences and Research, Hyderabad, was done. Their CTG traces were correlated with their intraoperative findings such as meconium stained liquor; nuchal cord and APGAR score at birth.

Results: Out of these 104 primigravida who underwent emergency caesarean section for nonreassuring fetal status, 63.4\% had CTG with decelerations-Non reactive, $28 \%$ had a CTG trace with persistent decreased variability while $7.6 \%$ had a reactive CTG with meconium stained liquor. Among patients with CTG trace showing decelerations $54.5 \%$ had meconium stained liquor, $28.7 \%$ had cord around the neck and $43.9 \%$ had low APGAR scores at birth. Among the group of patients with decreased variability $63.4 \%$ had meconium stained liquor, $30 \%$ had cord around the neck and $30 \%$ had low APGAR scores at birth. There were 8 patients who had reactive CTG with meconium stained liquor, among them only 3 had low APGAR scores.

Conclusions: Cardiotocography positively correlates with meconium stained liquor and APGAR scores at birth, but not with the presence of nuchal cord. Hence, judicious interpretation of CTG and introduction of another noninvasive, cost effective and acceptable test to detect non reassuring fetal status is warranted to prevent unnecessary caesarean sections.
\end{abstract}

Keywords: APGAR, Cardiotocography, Caesarean, Meconium stained liquor, Nuchal cord, Nonreassuring fetal status, Primigravida

\section{INTRODUCTION}

Caesarean section rates are on a rise. Caesarean section not only has a risk of neonatal and maternal morbidity but also has an effect on future pregnancies. The most common indication for emergency caesarean section is fetal distress. Nonreassuring fetal status (NRFS) has now replaced the term fetal distress. ${ }^{1}$ Intrapartum fetal heart monitoring, by intermittent fetal heart monitoring or continuous electronic cardiotocography (CTG) tracing are the only methods to diagnose NRFS during labour. 
However, these methods have low predictive value due to inter and intraobserver variation. ${ }^{2}$ CTG is influenced by hypoxic, metabolic or qualitative maternal blood alterations. Besides bradycardia and tachycardia , lack of variability, flat/smooth fetal heart rate (FHR) baseline and decelerations are also suggestive of hypoxic injury. ${ }^{3}$ Meconium stained liquor (MSL) may also indicate fetal distress in $12-16 \%$ of primigravida. ${ }^{4}$ It may or may not reflect as abnormal fetal heart rate. Higher rate of primary caesarean section in labour is attributed to the widespread use of electronic fetal monitoring in detecting abnormal fetal heart patterns. However, not all foetuses with abnormal fetal heart pattern have adverse perinatal outcome. The efficacy of electronic fetal heart monitoring in predicting adverse perinatal outcome has been questioned often. Therefore, to analyse the cause of rising caesarean section rate, a study to correlate the intraoperative findings in primigravida (who underwent emergency caesarean section for fetal distress) with cardiotocographic findings is warranted.

\section{Aim}

The purpose of this study is to demonstrate the correlation of intraoperative findings and neonatal outcome in primigravida undergoing emergency caesarean section for nonreassuring fetal status with cardiotocography.

\section{METHODS}

It was a retrospective observational study conducted in the department of Obstetrics and Gynecology at AIMSR. 104 primigravida who underwent emergency caesarean section from 2016 to 2017 for nonreassuring fetal status were included in the study. For each patient continuous cardiotocographic monitoring was performed during labour. Their CTG traces were collected from their medical records. All of them underwent emergency caesarean section due to non-reassuring fetal status. Intraoperative findings during caesarean section were obtained from their operative notes. The signs of nonreassuring fetal status on CTG were a trace showing late or variable decelerations or persistent decreased variability. Patients with a normal CTG trace but liquor showing significant meconium was also considered as NRFS. Post data collection, based on the type of CTG trace during labour, they were divided into three groups as follows- Group A- CTG showing decelerations; Group B- CTG showing persistent decreased variability; Group C- normal CTG. Intraoperative findings that were studied were meconium stained liquor, cord around the neck and APGAR at birth. They were correlated with the type of CTG trace in labour. Statistical tests that were applied were Chi square tests using SPSS data.

\section{RESULTS}

Out of these 104 primigravida undergoing emergency caesarean section for non-reassuring fetal status, $63.4 \%$ had Group A CTG, 28\% had Group B CTG while 7.6\% had a reactive CTG with meconium stained liquor (Group C).

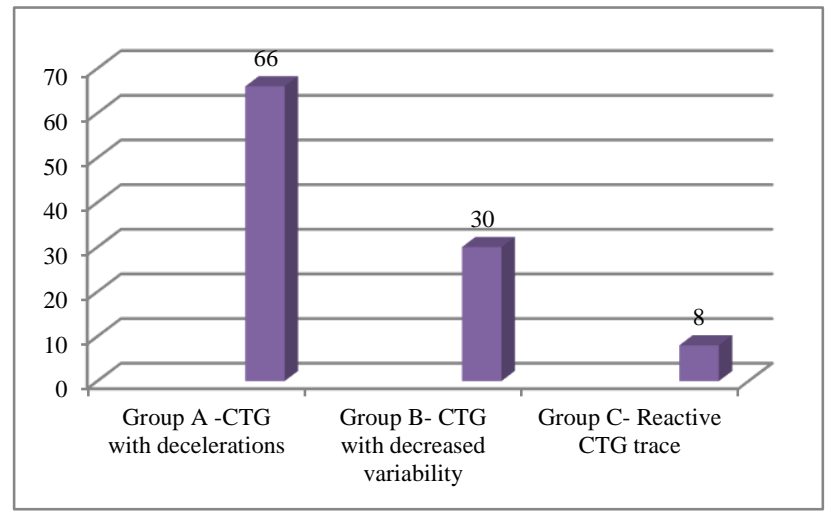

Figure 1: Types of CTG traces.

Table 1: CTG trace and colour of liquor.

\begin{tabular}{|llll|}
\hline & $\begin{array}{l}\text { Meconium stained } \\
\text { liquor }\end{array}$ & Clear & Total \\
\hline Group A & 30 & 36 & 66 \\
\hline Group B & 11 & 19 & 30 \\
\hline Group C & 8 & 0 & 8 \\
\hline Total & 49 & 55 & 104 \\
\hline
\end{tabular}

Out of the group with nonreactive CTG showing decelerations, $54.5 \%$ had meconium stained liquor while remaining $45.5 \%$ had clear liquor. With patients with CTG trace showing decreased variability $63.4 \%$ had meconium stained liquor while $36.6 \%$ had clear liquor. Out of 104 patients there were 8 patients who had a reactive CTG trace and had meconium stained liquor. Chi square test found a statistically significant association between colour of liquor and abnormal CTG trace. Out of the 104 deliveries, 34 babies were born with a nuchal cord.

Table 2: CTG findings and nuchal cord at birth.

\begin{tabular}{|llll|}
\hline & $\begin{array}{l}\text { Cord } \\
\text { around the } \\
\text { neck }\end{array}$ & $\begin{array}{l}\text { No cord } \\
\text { around the } \\
\text { neck }\end{array}$ & Total \\
\hline Group A & 19 & 47 & 66 \\
\hline Group B & 10 & 20 & 30 \\
\hline Group C & 5 & 3 & 8 \\
\hline
\end{tabular}

Among the primigravidas showing Group A CTG trace, $28.7 \%$ had a cord around the neck. One third patients with Group B CTG trace had a nuchal cord. In the group $\mathrm{C}$ where CTG was reactive but they had meconium stained liquor, out of 8 babies, 5 babies had cord around the neck. By Chi square test there was no statistically significant correlation between CTG trace and nuchal cord. The total babies with normal APGAR were 63 while 41 had low APGAR score at birth. 
Table 3: APGAR at birth and CTG trace in labour.

\begin{tabular}{|llll|}
\hline & Normal APGAR & Low APGAR & Total \\
\hline Group A & 37 & 29 & 66 \\
\hline Group B & 21 & 9 & 30 \\
\hline Group C & 5 & 3 & 8 \\
\hline
\end{tabular}

43.9\% of the patients with Group A trace had babies with low APGAR score while 30\% patients with Group B trace had low APGAR scores at birth. In the group C, 3 babies had low APGAR scores. The correlation between APGAR scores at birth and CTG tracing was found to be statistically significant by Chi square test. $56.1 \%$ of patients with Group A trace and $70 \%$ of patients with Group B trace had babies with normal APGAR. This could be due to early decision to delivery by caesarean section.

\section{DISCUSSION}

Cardiotocography (CTG) has emerged as a modern noninvasive tool in detecting nonreassuring fetal status in the last decade. Its reliability as a sole tool in diagnosing fetal distress is questionable and can lead to unnecessary rise in caesarean section rates. The present study was done to correlate the intraoperative findings and neonatal outcome with CTG trace in patients where emergency caesarean was done for non-reassuring fetal status.

The most common cause of emergency caesarean section among primigravidas in our centre is Non reassuring fetal status or fetal distress which was similar to many studies. ${ }^{5-7}$

The cardiotocographic findings suggestive of fetal distress in our study were presence of late or variable decelerations or decreased variability that was persistent. This was similar to study done by Low et al which states that decelerations, especially prolonged bradycardia, late decelerations, and severe variable decelerations are indicative of fetal distress and should prompt the clinician to evaluate and initiate intrauterine resuscitation with consideration for delivery of the fetus as indicated. ${ }^{8}$

Meconium stained liquor was found in $49.07 \%$ of primigravida who underwent caesarean section due to fetal distress in a study done by Mundhra et al, while in our study it was $47.1 \% .^{9}$ In another study done in South India the presence of meconium stained amniotic fluid with abnormal heart rate patterns was $23.8 \%$ while clear liquor with abnormal heart rate trace was $37.5 \%$ while in our study $47.1 \%$ patients had MSAF with CTG abnormality while $52.9 \%$ had clear liquor and abnormal CTG showing that colour of liquor may not always accurately translate into non reassuring trace on CTG. ${ }^{10}$

Presence of meconium stained liquor was highest in CTG showing variable or late decelerations followed by decreased beat to beat variability and this association was found to be statistically significant. This was in contrast to a study done by Sunita et al which found statistical association of meconium stained liquor only with late decelerations and not with decreased beat to beat variability. ${ }^{11}$ There are few studies stating the ominous effect of loss of beat to beat variability and its effect on fetal outcome. Hence even persistent low beat to beat variability should be seen with high index of suspicion for fetal distress. 8 patients, in our study had a reactive CTG trace with meconium stained liquor which is similar to a study by Desai et al where $30 \%$ of cases of meconium stained liquor had reactive CTG trace. ${ }^{12}$ Though meconium stained liquor has a significant association with abnormal CTG in our study, all parameters of a CTG may be normal despite the presence of meconium stained liquor. Therefore decision to deliver should be based on overall assessment and not merely on CTG trace.

In our study only one third of primigravidas with abnormal CTG had nuchal cord and this association was not found to be statistically significant. Nuchal cord leading to fetal distress has been reported in few studies. Multiple cord entanglement and tight cord are more often associated with fetal distress when compared to single cord in a study by Janet et al. ${ }^{13}$ Hence presence of a single loop of cord may not cause abnormal fetal heart pattern in most of the cases as shown in our study.

Various studies such as Ozden et al, found positive correlation between abnormal CTG (with late decelerations and decreased variability) and low APGAR score at birth. ${ }^{14}$ Similar observation was noted in our study where abnormal CTG with late deceleration was found in $43.9 \%$ of babies with low APGAR scores and there was a statistically significant association between them. This was similar to study by Salustiono et al, where prolonged decelerations were associated with low APGAR in $30.1 \%$ of patients. ${ }^{15}$ The high prevalence of normal APGAR 58.7\% in patients with abnormal trace, in our study, could be due to early intervention by caesarean section and inaccessibility to fetal scalp blood sampling to confirm acidosis. This is in contrast to western studies where normal APGAR with abnormal CTG is seen in only $15 \%$ of patients. Hence intrapartum electronic fetal monitoring is beneficial in improving fetal outcome though its judicious interpretation is warranted to curb the rising caesarean section rates.

\section{CONCLUSION}

Cardiotocography is an essential non-invasive tool in monitoring intrapartum events. CTG abnormalities such as decelerations and decreased beat to beat variability are significantly associated with presence of meconium stained liquor and low APGAR at birth. However a nonreassuring fetal trace may not always translate into abnormal fetal outcome hence carditocography should not be used as a sole decision maker to deliver by caesarean section. Confirmation of fetal acidosis by fetal blood sampling has not got universal acceptance as it is 
invasive. Hence introduction of a noninvasive, universally acceptable and cost effective method to diagnose intrapartum non-reassuring fetal status to bridge the gap between a cardiotocographic trace and decision of emergency caesarean section is the need of the hour.

Funding: No funding sources

Conflict of interest: None declared

Ethical approval: Not required

\section{REFERENCES}

1. Gravett C, Eckert LO, Gravett MG, Dudley DJ, Stringer EM, Mujobu TBM, et al. Non-reassuring fetal status: Case definition \& guidelines for data collection, analysis, and presentation of immunization safety data. Vaccine. 2016;34(49):6084-92.

2. Blackwell SC, Grobman WA, Antoniewicz L, Hutchinson M, Gyamfi Bannerman C. Interobserver and intraobserver reliability of the NICHD 3-Tier Fetal Heart Rate Interpretation System. Am J Obstet Gynecol. 2011;205:1-5.

3. Ancăr V, Ionescu C. Obstetrică. Editura Medicală Naţională: Bucureşti; 2000: 39-44.

4. Maymon E, Chaim W, Furman B, Ghezzi F, Shoham Vardi I, Mazor M. Meconium stained amniotic fluid in very low risk pregnancies at term gestation. Eur J Obstet Gynecol Reprod Biol. 1998;80:169-73.

5. Kohli UA, Singh S, Dey M, Bal HK, Seth A. Antenatal risk factors in emergency caesarean sections done for fetal distress. Int $\mathrm{J}$ Reprod Contracept Obstet Gynecol. 2017;6:2421-6.

6. Chauhan SP, Magann EF, Scott JR,Scardo JA, Hendrix NW, Martin JN jr. Cesarean delivery for fetal distress: rate and risk factors. Obstet Gynecol Survey. 2003;58(5):337-50.

7. Roy KK, Baruah J, Kumar S, Deorari AK, Sharma JB, Karmakar D. Cesarean section for suspected fetal distress, continuous fetal heart monitoring and decision to delivery time. Ind $\mathbf{J}$ Pediatrics. 2015;75(12):1249-52.
8. Low JA, Victory R, Derrick EJ. Predictive value of electronic fetal monitoring for intrapartum fetal asphyxia with metabolic acidosis. Obstet Gynecol. 1999;93:285-91.

9. Mundhra R, Agarwal M. Fetal Outcome in Meconium Stained Deliveries. JCDR. 2013;7(12):2874-6.

10. Kumar BV, Raj SV, Devi S. Abnormal fetal heart tracing patterns in patients with meconium staining of amniotic fluid and its association with perinatal outcomes. Int J Reprod Contracept Obstet Gynecol 2015;4:629-33.

11. Sunitha C, Rao PS, Prajwal S, Bhat RK. Correlation of intrapartum electronic fetal monitoring with neonatal outcome. Int $\mathrm{J}$ Reprod Contracept Obstet Gynecol. 2017;6:2174-9.

12. Desai D, Maitra N, Patel P. Fetal heart rate patterns in patients with thick meconium staining of amniotic fluid and its association with perinatal outcome. International J Reproduction, Contraception, Obstetrics Gynecol. 2017;6(3):1030-5.

13. Larson JD, Rayburn WF, Crosby S, Thurnau GR. Multiple nuchal cord entanglements and intrapartum complications. Am J Obstet Gynecol. 1995;173:1228-31.

14. Ozden S, Demirci F. Significance for fetal outcome of poor prognostic features in fetal heart rate traces with variable decelerations. Arch Gynecol Obstet. 1999;262(3-4):141-9.

15. Assunção SEM, Bonini CJAD, Maria IS, Rodrigo R, Marcelo Z. Low Apgar scores at 5 minutes in a low risk population: maternal and obstetrical factors and postnatal outcome. Rev Assoc Med Bras. 2012;58(5):587-93.

Cite this article as: Bhatia N, Krishna Kumari M. Intraoperative findings in primary caesarean section for non-reassuring fetal status and its correlation with cardiotocography. Int J Reprod Contracept Obstet Gynecol 2018;7:2351-4. 